Article

\title{
Wind-Photovoltaic-Energy Storage System Collaborative Planning Strategy Considering the Morphological Evolution of the Transmission and Distribution Network
}

\author{
Defu Cai ${ }^{1}{ }^{1}$, Zuowei Wang ${ }^{1}$, Shihong Miao ${ }^{2, *}$, Rusi Chen ${ }^{1}$, Zhong Zheng $^{2}$ and Kunpeng Zhou ${ }^{1}$ \\ 1 State Grid Hubei Electric Power Research Institute, Wuhan 430077, China; defucai@foxmail.com (D.C.); \\ wangzw5@hb.sgcc.com.cn (Z.W.); chenrs17@163.com (R.C.); idkpzhou@163.com (K.Z.) \\ 2 State Key Laboratory of Advanced Electromagnetic Engineering and Technology, School of Electrical and \\ Electronic Engineering, Huazhong University of Science and Technology, Wuhan 430074, China; \\ zzheng@hust.edu.cn \\ * Correspondence: shmiao@hust.edu.cn
}

check for

updates

Citation: Cai, D.; Wang, Z.; Miao, S.;

Chen, R.; Zheng, Z.; Zhou, K.

Wind-Photovoltaic-Energy Storage

System Collaborative Planning

Strategy Considering the

Morphological Evolution of the

Transmission and Distribution

Network. Energies 2022, 15, 1481.

https://doi.org/10.3390/en15041481

Academic Editor: Tapas Mallick

Received: 31 December 2021

Accepted: 9 February 2022

Published: 17 February 2022

Publisher's Note: MDPI stays neutral with regard to jurisdictional claims in published maps and institutional affiliations.

Copyright: () 2022 by the authors Licensee MDPI, Basel, Switzerland. This article is an open access article distributed under the terms and conditions of the Creative Commons Attribution (CC BY) license (https:// creativecommons.org/licenses/by/ $4.0 /)$.

\begin{abstract}
The collaborative planning of a wind-photovoltaic (PV)-energy storage system (ESS) is an effective means to reduce the carbon emission of system operation and improve the efficiency of resource collaborative utilization. In this paper, a wind-PV-ESS collaborative planning strategy considering the morphological evolution of the transmission and distribution network is proposed. Firstly, aiming at the optimal economy of transmission and distribution network and considering the constraints of safe and stable operation of the system, the planning model of the transmission network based on DC power flow and the planning model of the distribution network based on AC power flow are constructed. Further, considering the coupling interaction between the transmission and distribution networks, a collaborative planning model of transmission and distribution networks based on second-order cone relaxation (SOCR) is constructed. Secondly, in order to reduce the computational complexity of the model and ensure the global optimality of the model solution, a fast model solution method based on heterogeneous decomposition architecture is proposed. Thirdly, the multiple driving factors of the morphological evolution of transmission and distribution network are analyzed, the morphological evolution path and typical characteristics of transmission and distribution network are determined, and a wind-PV-ESS collaborative planning strategy considering the morphological evolution of a transmission and distribution network is proposed. Finally, the results show that, compared with the sprouting period, the overall economy of the development period and maturity period is improved by $3342 \mathrm{k} \$$ and $5751 \mathrm{k} \$$ respectively, and the effectiveness and necessity of the collaborative planning strategy proposed in this paper is verified.
\end{abstract}

Keywords: transmission and distribution network; morphological evolution; second order cone relaxation; heterogeneous decomposition architecture; collaborative planning strategy

\section{Introduction}

New energy power generation has the characteristics of environment-friendly, low carbon emission, and rich resources. In recent years, it has attracted extensive attention from academia and industry [1]. With the proposal of the goal of carbon peak and carbon neutralization, accelerating the construction of a new power system based on new energy and promoting the transformation and upgrading of energy consumption and production has gradually become one of the important strategic objectives of power grid development and construction. However, considering the physical properties and dynamic characteristics of new energy power generation, large-scale new energy access will increase the randomness, volatility and uncertainty of the system, and bring severe challenges to the safe, stable, clean and efficient operation of the power grid [2]. 
In recent years, collaborative planning and operation optimization of an active distribution network (ADN) considering large-scale new energy access has gradually become a hot academic research topic. Ref. [3] established a day-ahead optimization model of ADN considering different types of distributed generation, such as wind power generation, and photovoltaic (PV) power generation. Ref. [4] takes the minimum net present value of the total system cost as the optimization objective, and a joint multistage expansion planning strategy of ADN based on mixed integer linear programming (MILP) is proposed. At the same time, in order to further improve the model reliability and application value, the new energy output uncertainty also needs to be considered in the model. Considering the uncertainty of the PV and wind power generation, the energy dispatch strategy designed by the method of the chance-constrained programming is proposed in [5]. Ref. [6] proposed a probabilistic power flow calculation algorithm for ADN, in which the Taylor series and Gram-Charlier expansion are used to improve the efficiency and convergence.

However, the disorderly access of large-scale distributed new energy sources may lead to a series of problems, such as difficulties in energy consumption and operational instability [7,8]. Ref. [9] presents an enhanced operation and control of DC microgrid systems, which are based on photovoltaic modules, ESS, and DC load. To estimate the state of charge and state of health of $\mathrm{LiFePO}_{4}$ batteries simultaneously, a reliable and robust observer is proposed in [10]. For the adverse effects of PV module losses on power system stability, ref. [11] proposes an optimum solution for fault finding, tracking, and clearing for PV systems.

With the development of energy storage technology and cost reduction, the introduction of an energy storage system (ESS) provides a new way to solve the above problems [12]. Ref. [13] presented an overview on the employment of ESS technologies in the planning and operation of distribution systems through the literature survey. Ref. [14] proposed a direct control strategy to track the deviation of the wind power plan in order to improve the overall economy of the wind-energy storage power station. Ref. [15] presents a unified decision-making structure that consists of network partitioning and optimal operational planning issues in order to determine the optimal allocation of wind farms (WFs), PV parks, and ESS in each created partition. Ref. [16] studied the wind-PV-ESS control method with the goal of smoothing out new energy fluctuations, promoting clean energy consumption, and peak and valley reduction. Ref. [17] established a solution model of energy storage dynamic planning and configuration based on a bi-objective approach with minimum capacity and charging and discharging power and, then, the improved heuristic algorithm is used to determine the multi-objective optimal planning configuration of the ESS.

With the large-scale access of distributed new energy, ESS and power electronics, the distribution network is gradually changing from traditional distribution network to ADN. Therefore, the concept of considering distribution network as a transmission network load node is no longer applicable to the active distribution network, and it is urgent to adopt the transmission-distribution cooperative approach for power system optimization planning to improve the efficiency of cooperative resource utilization and overall system economy. In view of this, some of the literature has studied transmission and distribution cooperative optimization algorithms. The current ideas of solving transmission and distribution cooperative optimization problems can be broadly divided into two branches: centralized optimization algorithms and distributed optimization algorithms [18]. Aiming at the transmission and distribution coordinated economic dispatch (TDCED) problems, ref. [19] proposed a heterogeneous decomposition algorithm based on the locational marginal prices (LMPs) and boundary load injection. However, the heterogeneous decomposition algorithm may have the defects of low solution efficiency and convergence difficulty in the solution process. To solve this problem, ref. [20] proposed two modification methods of a heterogeneous decomposition algorithm which are based on a penalty function and the sensitivity of LMP to the load injection. At the same time, ref. [21] proposed a non-iterative decoupled method for the coordinated solution of the robust optimal power flow in the transmission and distribution networks. The above research mainly focuses on transmission 
and distribution cooperative day-ahead dispatching, real-time dispatching and optimal power flow problems. With the increasing coupling of power grids and the increasing abundance of adjustable resources in the system, the coupling interaction of transmission and distribution networks at the planning level also has certain research value.

In addition, the above studies all focus on the current form of the power grid and fail to take into account the impact of the evolution of the grid form on the system optimization planning results, an oversight which has strong limitations. Ref. [22] analyzed the composition of the morphological development drivers of the power grid and the typical paths of the evolution of the grid morphology, and explored the complex effects of the compounding of multiple drivers on the planning problem. Ref. [23] provided an outlook on the future multiple morphologies of the power system and discussed the impact and changes of power system planning in the future morphologies. It is of theoretical importance to accurately characterize the mapping relationship between grid morphology evolution and optimal planning, and to develop a collaborative planning scheme for the system that takes into account the multiple driving paths of morphology evolution.

In summary, the existing literature provides a certain research basis for the transmission and distribution network cooperative optimization problem. However, the existing studies on transmission and distribution cooperative optimization mainly focus on the optimal power flow and day-ahead dispatching level, and fail to fully consider the impact of transmission and distribution network coupling interaction on the planning results. In addition, the current research on power system planning is mainly focused on the current system form, and there is little literature to study the impact of the evolution of transmission and distribution network form on the system planning strategy driven by multiple factors, which lacks relevance and foresight.

To address the above problems, this paper proposes a wind-photovoltaic-energy storage system collaborative planning strategy considering the morphological evolution of transmission and distribution networks.

The contributions of this paper are summarized as follows:

(1) A DC power flow-based transmission network planning model and an AC power flow-based distribution network planning model are constructed. The transmission and distribution network wind-PV-ESS cooperative convex optimization model is then obtained by second-order cone relaxation (SOCR).

(2) A model-solving framework based on heterogeneous decomposition is designed to ensure the convergence and global optimality of the model.

(3) The typical stages of transmission and distribution network morphology evolution are divided and the quantitative characteristics of each typical stage are analyzed.

(4) A cooperative planning strategy for scenery storage that takes into account the transmission and distribution network morphology evolution is proposed.

This paper is organized as follows. Section 2 describes the wind-PV-ESS collaborative planning model for transmission and distribution networks. Then, Section 3 analyzes the typical stages of transmission and distribution networks, and wind-PV-ESS planning strategies in transmission and distribution network considering the morphological evolution is proposed. Numerical simulations with the T6D7D9 system are performed to show the effectiveness of the proposed strategy.

\section{Transmission and Distribution Network Wind-PV-ESS Collaborative Planning Model}

The construction of the wind-PV-ESS collaborative planning model for transmission and distribution networks is the basis for planning strategy development, and its general expression form can be written as follows:

$$
\min f_{T-D}=\min \left[f^{\text {trans }}\left(\boldsymbol{X}^{\text {trans }, i}, \boldsymbol{M}^{\text {trans }, i}\right)+f^{d i s}\left(\boldsymbol{X}^{d i s, j}, \boldsymbol{M}^{d i s, j}\right)\right]
$$




$$
\begin{gathered}
\left\{\begin{array}{l}
g^{\text {trans }}\left(\boldsymbol{X}^{\text {trans }, i}, \mathbf{M}^{\text {trans }, i}\right) \leq 0 \\
h^{\text {trans }}\left(\boldsymbol{X}^{\text {trans }, i}, \boldsymbol{M}^{\text {trans }, i}\right)=0
\end{array}\right. \\
\left\{\begin{array}{l}
g^{d i s}\left(\boldsymbol{X}^{\text {dis }, j}, \boldsymbol{M}^{\text {dis }, j}\right) \leq 0 \\
h^{\text {dis }}\left(\boldsymbol{X}^{\text {dis }, j}, \boldsymbol{M}^{\text {dis }, j}\right)=0
\end{array}\right. \\
\left\{\begin{array}{c}
g^{\text {con }}\left(\boldsymbol{M}^{\text {con }, k}\right) \leq 0 \\
h^{\text {con }}\left(\boldsymbol{M}^{\text {con }, k}\right)=0
\end{array}\right.
\end{gathered}
$$

where $f_{T-D}$ is the general objective function of the transmission and distribution cooperative planning model; $f^{\text {trans }}, f^{\text {dis }}$ are the general objective function of the transmission network and the general objective function of the distribution network, respectively; $X^{\text {trans, } i}, X^{d i s, j}$ are the optimization decision variables (wind power, PV, energy storage unit installation location, ratio, thermal power unit output, etc.) of the $i$ th transmission network and the $j$ th distribution network, respectively; $\boldsymbol{M}^{\text {trans, } i}{ }_{,} \boldsymbol{M}^{d i s, j}, \boldsymbol{M}^{\boldsymbol{c o n}, \boldsymbol{k}}$ are the general decision variables (system voltage magnitude, phase angle, power delivered by the contact line, etc.) of the $i$ th transmission network, the $j$ th distribution network and the $k$ th transmission and distribution contact power, respectively.

Considering the structural characteristics of the transmission and distribution networks and the overall computational efficiency of the model, this paper constructs the transmission network scenic storage cooperative planning model considering DC power flow constraint and the distribution network scenic storage cooperative planning model based on AC power flow, further considers the transmission and distribution network coupling, and uses SOCR to perform convex relaxation on the non-convex terms of the distribution network model and, finally, the SOCR-based transmission and distribution cooperative convex optimization model is obtained.

\subsection{Transmission Network Planning Model}

\subsubsection{Objective Function}

The transmission network scenery storage synergy planning model optimization objective is system economic optimization, which is mainly achieved by considering the transmission network thermal unit output cost, distribution network power purchase cost, wind power, photovoltaic, energy storage investment completion cost and wind-PV abandonment penalty. The specific expressions are as follows.

$$
\begin{gathered}
o b j^{\text {trans }}=o b j_{g e n}^{\text {trans }}+o b j_{\text {rev }}^{\text {trans }}+o b j_{i n v}^{\text {trans }}+o b j_{a b a}^{\text {trans }} \\
o b j_{g e n}^{\text {trans }}=\sum_{t \in T} \sum_{i \in N_{G}}\left(a_{i}+b_{i} P_{i, t, g}^{\text {trans }}+c_{i}\left(P_{i, t, g}^{\text {trans }}\right)^{2}\right) \\
o b j_{\text {rev }}^{\text {trans }}=\sum_{t \in T} \sum_{i \in N_{\text {root }}} l_{i, t}^{\text {trans }} P_{i, t}^{\text {root }} \\
o b j_{\text {inv }}^{\text {trans }}=\sum_{i \in N_{\text {trans }}} k_{\text {dep }}\left(c_{i, w}^{\text {trans }}+c_{i, p v}^{\text {trans }}+c_{i, c}^{\text {trans }}\right) \\
o b j_{a b a}^{\text {trans }}=k_{\text {pub }}^{\text {trans }}\left(P_{w, a b a}^{\text {trans }}+P_{p v, a b a}^{\text {trans }}\right) \\
k_{\text {dep }}=\left(1-k_{c}\right) \frac{i(1+i)^{n}}{(1+i)^{n}-1}
\end{gathered}
$$

where $o b j^{\text {trans }}$ is the objective function of the transmission network planning model; $o b j_{\text {gen }}^{\text {trans }}, o b j_{\text {rev }}^{\text {trans }}, o b j_{i n v}^{\text {trans }}, o b j_{a b a}^{\text {trans }}$ are the transmission network generation cost, distribution network power purchase cost, equipment installation cost and wind-PV abandonment 
penalty, respectively; $c_{i}, b_{i}, a_{i}$ are the quadratic, primary and constant coefficients of the transmission network thermal unit generation cost, respectively; the set of transmission network generator nodes, $N_{G}, N_{\text {root }}, N_{\text {trans }}$, are the set of root nodes connected to the distribution network, the set of all transmission network nodes, and the set of transmission network nodes, respectively; $P_{i, t, g}^{\text {trans }}, P_{i, t}^{\text {root }}$ are the power output of thermal units and the power transmitted to the distribution network at node $i$ time $t ; l_{i, t}^{\text {trans }}$ is the price of electricity sold in the transmission network at node $i$ time $t ; k_{d e p}, k_{p u b}^{\text {trans }}$ are the depreciation coefficient of equipment and the penalty coefficient of abandoned scenery in the transmission network; $c_{i, w}^{\text {trans }}, c_{i, p v}^{\text {trans }}, c_{i, c}^{\text {trans }}$ are the installed capacity of wind power, PV and ESS in the transmission network at node $i ; P_{w, a b a}^{\text {trans }}, P_{p v, a b a}^{\text {trans }}$ are the total amount of abandoned wind and PV in the transmission network, respectively; $k_{c}$ is the residual value rate of equipment; $i$ represents the bank interest rate,; and $n$ represents the life cycle of equipment.

\subsubsection{Constraint Condition}

The transmission network wind-PV-ESS cooperative planning model constructed in this paper is divided into the optimization planning layer and the operation and scheduling layer, and the specific expressions of its constraints are as follows.

(1) System investment capacity constraint

$$
\left\{\begin{array}{l}
c_{i, w}^{\text {trans }} \leq c_{i, w, \max }^{\text {trans }} \\
c_{i, p v}^{\text {trans }} \leq c_{i, p v, \max }^{\text {trans }} \\
c_{i, c}^{\text {trans }} \leq c_{i, c, \max }^{\text {trans }}
\end{array}\right.
$$

where $c_{i, w, \text { max }}^{\text {trans }}, c_{i, p v \text {, } \operatorname{trax}}^{\text {trans }}, c_{i, c, \text { max }}^{\text {trans }}$ are the maximum installed capacity of wind power, PV units and ESS at node $i$, respectively [24].

(2) Active balance constraint

$$
\sum_{i \in N_{\text {trans }}}\left(P_{i, t, w}^{\text {trans }}+P_{i, t, p v}^{\text {trans }}+P_{i, t, \mathrm{c}}^{\text {trans }}-P_{i, t, l o a d}^{\text {trans }}\right)+\sum_{i \in N_{G}} P_{i, t, g}^{\text {trans }}-\sum_{l \in N_{L}} P_{l, t}^{\text {loss }}-\sum_{i \in N_{\text {root }}} P_{i, t}^{\text {root }}=0, \forall t \in T
$$

where $P_{i, t, w}^{\text {trans }}, P_{i, t, p v}^{\text {trans }}, P_{i, t, \mathrm{c}}^{\text {trans }}, P_{i, t, l \text { toad }}^{\text {trans }}$ are the wind turbine output, PV generator output, ESS output and load of the system at time $t$ of node $i$, respectively, and considering that there may be two states of charging/discharging in the ESS it is assumed that the output of the energy storage system is negative when it is in charging state and positive when it is in discharging state, and the ESS can only be in one of the charging/discharging states at any time; $N_{L}$ is the set of transmission network branches; $P_{l, t}^{\text {loss }}$ is the network loss of transmission network branch $l$ at time $t$.

(3) New energy unit constraints

$$
\left\{\begin{array}{l}
P_{i, t, w}^{\text {trans }} \leq P_{i, t, w, a v a}^{\text {trans }} \\
P_{i, t, p v}^{\text {trans }} \leq P_{i, t, p v, a v a}^{\text {trans }}
\end{array}\right.
$$

where $P_{i, t, w, a v a}^{\text {trans }} P_{i, t, p v, a v a}^{\text {trans }}$ are the maximum available power of wind and PV units at node $i$ of the transmission network at time $t$, respectively. 
(4) ESS constraints

$$
\left\{\begin{array}{l}
-p_{i, c, \text { max }}^{\text {trans }} \leq P_{i, t, c}^{\text {trans }} \leq p_{i, c, \text { max }}^{\text {trans }} \\
\left|\sum_{t \in T} P_{i, t, c}^{\text {trans }}\right| \leq c_{i, c}^{\text {trans }} \\
S_{i, t, c}^{\text {trans }}-S_{i, t-1, c}^{\text {trans }}=\frac{P_{i, t, c}^{\text {trans }} \eta_{c}}{c_{i, c}^{\text {trans }}} \\
S_{c, \text { min }}^{\text {trans }} \leq S_{i, t, c}^{\text {trans }} \leq S_{c, \text { trans }}^{\text {tran }}
\end{array}\right.
$$

where $p_{i, c, \max }^{\text {trans }}$ is the invested power of ESS at node $I ; c_{i, c}^{\text {trans }}$ is the invested capacity of ESS at node $i$ of the transmission network; $c_{i, c, \max }^{\text {trans }}$ is the upper limit of ESS at node $i$ of the transmission network; $S_{i, t, c}^{\text {trans }}$ is the State of Charge(SOC) of ESS at node $i ; \eta_{c}$ is the charging/discharging efficiency of ESS, where charging/discharging efficiency is reciprocal; and $S_{c, \text { trax }}^{\text {trans }}, S_{c, \text { min }}^{\text {trans }}$ are the upper/lower limit of SOC of ESS.

(5) System security and stable operation constraints

$$
\begin{aligned}
U_{\min }^{\text {trans }} \leq & U_{i, t}^{\text {trans }} \leq U_{\max }^{\text {trans }}, \forall i \in N_{\text {trans }} \\
0 \leq & I_{l, t}^{\text {trans }} \leq I_{l, \text { max }}^{\text {trans }}, \forall l \in N_{L} \\
& \left\{\begin{array}{l}
T_{i, \text { on }}^{\text {trans }} \geq T_{o n, \text { min }} \\
T_{i, \text { off }}^{\text {trans }} \geq T_{o f f, \text { min }}
\end{array}\right.
\end{aligned}
$$

where $U_{i, t}^{\text {trans }}$ is the voltage of the transmission network node at node $i$ in period $t$, and $U_{\max }^{\text {trans }}, U_{\min }^{\text {trans }}$ are the upper and lower voltage limits of the transmission network node, respectively; $I_{l, t}^{\text {trans }}$ is the load capacity of transmission network branch $l$, and $I_{l, \text { max }}^{\text {trans }}$ is the upper limit of load capacity of branch $l ; T_{i, o n}^{\text {trans }}, T_{i, \text { off }}^{\text {trans }}$ are the start-up time and shutdown time of the $i$ th unit of the transmission network, and $T_{o n, \min }, T_{o f f, \min }$ are the minimum start-up/shutdown time of the thermal units of the transmission network, respectively.

\subsection{Distribution Network Planning Model}

\subsubsection{Objective Function}

The optimization objective of the distribution network wind-PV-ESS planning model is also the optimal system economy, which mainly includes the cost of power purchase in the distribution network, the cost of equipment installation and the penalty of wind-PV abandonment, and the specific expressions are as follows.

$$
\begin{gathered}
o b j^{d i s}=o b j_{u p}^{d i s}+o b j_{i n v}^{d i s}+o b j_{a b a}^{d i s} \\
o b j_{u p}^{d i s}=\sum_{t \in T} l_{i, t}^{\text {trans }} P_{i, t, c o n}^{d i s}, i \in N_{c o n}^{d i s} \\
o b j_{i n v}^{d i s}=\sum_{i \in N_{d i s}} k_{d e p}\left(c_{i, w}^{d i s}+c_{i, p v}^{d i s}+c_{i, c}^{d i s}\right) \\
o b j_{a b a}^{d i s}=k_{p u b}^{d i s}\left(P_{w, a b a}^{d i s}+P_{p v, a b a}^{d i s}\right)
\end{gathered}
$$

where $o b j^{d i s}$ is the objective function of the distribution network; $o b j_{u p}^{d i s}, o b j_{i n v}^{d i s}, o b j_{a b a}^{d i s}$ are the cost of power purchase, equipment installation cost and wind-PV abandonment penalty of the distribution network, respectively; $P_{i, t, c o n}^{d i s}$ is the power purchase at time $t$ of the distribution network, for the convenience of analysis this paper only considers the scenario that only one node of the distribution network is connected to the transmission network; $N_{c o n}^{\text {dis }}$ is the node of the distribution network connected to the superior transmission network; $k_{p u b}^{d i s}$ is the depreciation coefficient of the distribution network equipment and 
the transmission network denotes the wind and light abandonment coefficient of the distribution network; $c_{i, w}^{d i s}, c_{i, p v}^{d i s}, c_{i, c}^{d i s}$ are the installed capacity of wind power, PV and ESS at node $i$ of the distribution network; and $P_{w, a b a^{\prime}}^{d i s} P_{p v, a b a}^{d i s}$ are the total amount of wind and PV abandonment of the distribution network, respectively.

\subsubsection{Constraint Condition}

For the operation and dispatching layer, the distribution network no longer considers only the active power balance, but the active-reactive power balance constraint and the AC power flow constraint, and the specific expressions are as follows.

(1) Active-reactive power balance constraint

$$
\left\{\begin{array}{l}
P_{i, t, w}^{d i s}+P_{i, t, p v}^{d i s}+P_{i, t, c}^{d i s}+P_{i, t, c o n}^{d i s}-P_{i, t, l o a d}^{d i s}-\sum_{l \in N_{L}(i)} P_{l, t}^{d i s}=0 \\
Q_{i, t, s v c}^{d i s}-Q_{i, t, l o a d}^{d i s}-\sum_{l \in N_{L}(i)} Q_{l, t}^{d i s}=0, \forall t \in T, i \in N_{d i s}
\end{array}\right.
$$

where $P_{i, t, w}^{d i s}, P_{i, t, p v}^{d i s}, P_{i, t, c}^{d i s}, P_{i, t, c o n}^{d i s}, P_{i, t, l o a d}^{d i s}$ are the wind turbine output, PV generator output, ESS charging and discharging power, active power purchased from the transmission network, and active load power of the distribution network at node $i$, time $t ; P_{l, t}^{\text {dis }}$ is the active power of branch $l ; Q_{i, t, s v c}^{d i s}, Q_{i, t, l o a d}^{d i s}$ are the SVC reactive power and load reactive power of the distribution network at node $i ; N_{L}(i)$ is the active power and reactive power of branch $l$; and $N_{d i s}$ is all branches of the distribution network containing node $i$ which denotes the set of all distribution network nodes.

(2) AC power flow constraint

Considering the distribution network structure characteristics, the AC power flow constraint is used to characterize the active power balance and reactive power balance of the distribution network, and its specific expressions are shown below:

$$
\left\{\begin{array}{l}
P_{l, t}^{d i s}=G_{l}^{d i s}\left(U_{i, t}^{d i s}\right)^{2}-G_{l}^{d i s} U_{i, t}^{d i s} U_{j, t}^{d i s} \cos \theta_{l, t}^{d i s}-B_{l}^{d i s} U_{i, t}^{d i s} U_{j, t}^{d i s} \sin \theta_{l, t}^{d i s} \\
Q_{l, t}^{d i s}=B_{l}^{d i s} U_{i, t}^{d i s} U_{j, t}^{d i s} \cos \theta_{l, t}^{d i s}-B_{l}^{d i s}\left(U_{i, t}^{d i s}\right)^{2}-G_{l}^{d i s} U_{i, t}^{d i s} U_{j, t}^{d i s} \sin \theta_{l, t}^{d i s}
\end{array}\right.
$$

where $i, j$ denote the first node and end node of branch $l$, respectively; $G_{l}, B_{l}$ are the conductance and susceptance value of branch $l$ of the distribution network, respectively; $U_{i, t}$ is the voltage amplitude of node $i$ at time $t$, respectively, and $\theta_{l, t}^{d i s}$ is the phase angle of branch $l$ of the distribution network at time $t$.

For the distribution network, the new energy unit constraint, ESS constraint and system safety and stability operation constraint are the same as those for the transmission network, so they are not repeated here. Since thermal units are not considered in the distribution network, the start-stop time constraint of thermal units is not involved in the safe and stable operation constraint of the distribution network.

\subsection{Transmission and Distribution Network Collaborative Planning Model}

For the transmission and distribution network, in addition to the operational constraints of each subsystem, it needs to satisfy the transmission and distribution network power interaction constraints:

$$
\boldsymbol{P}_{t}^{T-D} \leq P_{\max }^{T-D}, \forall t \in T
$$

where $\boldsymbol{P}_{t}^{T-D}$ is the transmission and distribution network transmission power matrix at time $t$, corresponding to the transmission network optimization variables $P_{i, t}^{\text {root }}$ and distribution network optimization variables $P_{i, t, c o n}^{d i s}$, respectively; and $P_{\max }^{T-D}$ is the upper limit of transmission and distribution network transmission power. 
At the same time, in view of the non-convex constraints involved in the distribution network scenic storage planning model, such as AC tidal current constraints, to ensure the solvability of the model in this paper, SOCR is further introduced to convert the distribution network AC tidal current constraints into second-order cone constraints that can be solved directly by mature commercial software after relaxation through variable definition, constraint equivalence deformation and relaxation [25].

In summary, this paper takes the overall economic optimality of transmission and distribution network as the goal and considers transmission network operation constraints, distribution network operation constraints and transmission-distribution coupling constraints, and constructs a transmission and distribution network wind-PV-ESS cooperative planning model. The specific expression form is as follows:

$$
\left\{\begin{array}{l}
o b j=\min \sum_{i \in M_{\text {trans }}} o b j_{i}^{\text {trans }}+\sum_{i \in M_{d i s}} o b j_{j}^{d i s} \\
\text { s.t eq }(6)-(13),(18),(19) \text { after SOCR }
\end{array}\right.
$$

\section{Wind-PV-ESS Planning Strategies in Transmission and Distribution Network Considering the Morphological Evolution}

3.1. Study on the Typical Characteristics of Transmission and Distribution Network Morphology Evolution Driven by Multiple Factors

With the new concept of the power system, the transmission and distribution network has been developed rapidly in recent years. Compared with the traditional power system, the future power system will undergo significant changes in the source-grid-load side, and the role of each subject in the traditional power system will be further transformed. The current transmission and distribution network planning research is mainly focused on the current morphology; it fails to consider the changes in the proportion of source-load resources with different types and characteristics, and does not analyze the impact of the changing role of transmission and distribution networks on the planning scheme, which is a significant limitation. Therefore, there is an urgent need to study the typical characteristics of transmission and distribution network morphology driven by multiple factors in order to determine the optimal planning scheme for a power system that takes into account the morphological evolution of transmission and distribution networks.

To facilitate the arithmetic analysis, this paper mainly considers three typical stages of transmission and distribution network morphology: the evolution-sprouting period, development period, and maturity period [26]. The multiple drivers and quantitative characteristics of the typical stages of grid morphology evolution are analyzed from three dimensions of source-grid-storage, respectively. First, the source-side morphological evolution is mainly reflected in the structural transformation of the power system from a thermal power generation-based power system to a new energy-based power system, which is mainly characterized by the increasing proportion of new energy in each typical stage of the system. At the same time, the evolution of the network side is mainly reflected in the transition of the distribution network from the traditional distribution network to the active distribution network, whose role and behavior will be fundamentally changed: the traditional distribution network (sprouting period) can be simply regarded as a transmission network load node, while the active distribution network (development period and maturity period) may have large-scale distributed new energy, and the power system gradually tends to flatten. In addition, unlike the traditional distribution network, the energy data coupling between the ADN and the transmission network is closer, so the necessity of transmission and distribution cooperative planning is also further highlighted. Finally, the evolution of the energy storage side is mainly reflected in the following: compared with the sprouting period of the grid, the development and maturity periods need to further consider the impact of ESS and other flexible regulation resources to the grid, while at the same time taking into account the development of energy storage technology; as the evolution of the transmission and distribution network continues to advance, the way in 
which the energy storage access system operates will gradually change from the traditional large-scale centralized access to centralized and distributed access at the same time.

In summary, this paper summarizes the main quantitative characteristics of each typical period of transmission and distribution network morphology evolution, as can be seen in Table 1.

Table 1. Comparison of characteristics of three typical morphological evolution periods of transmission and distribution network.

\begin{tabular}{cccc}
\hline & Sprouting Period & Development Period & Maturity Period \\
\hline $\begin{array}{c}\text { Distribution network Form } \\
\text { Percentage of new energy }\end{array}$ & Conventional distribution network & ADN & ADN \\
Percentage of ESS & $0 \%$ & $20 \%$ & $50 \%$ \\
Objective function & $/$ & Small-scale, distributed access & $\begin{array}{c}\text { Large-scale, centralized, } \\
\text { distributed access } \\
\text { Consider economics and } \\
\text { environment factors }\end{array}$ \\
\hline
\end{tabular}

\subsection{Wind-PV-ESS Collaborative Planning Strategy in Transmission and Distribution Networks} Based on Heterogeneous Decomposition Architecture

Based on the above research, this paper further proposes a cooperative planning strategy for wind-PV-ESS in transmission and distribution networks based on heterogeneous decomposition architecture. The upper layer is the optimization planning layer, which simultaneously determines the installation location and capacity of wind power, $\mathrm{PV}$ and ESS in the transmission and distribution network, and provides feedback to the lower layer on the site selection and capacity determination results. The lower layer is the operation scheduling layer, which determines the optimal power output scheme of multiple types of units in the transmission and distribution network and the interaction power of transmission and distribution network. Both the upper and lower layers achieve global optimization through the interaction of transmission and distribution network boundary information, and their specific optimization processes are as follows:

Step 1: Initialization of the program, importation of load data, initialization of transmission and distribution network structure and base variables, number of iterations ite $=1$.

Step 2: Determination of the typical periods of the transmission and distribution network under study and their quantitative characteristics, obtaining the boundary conditions of the optimization procedure.

Step 3: Optimization planning layer model solving to obtain the transmission and distribution network wind-PV-ESS siting and capacity setting scheme.

Step 4: Solve the model of operation and dispatching layer, obtain the optimal power plan of multiple types of units in the transmission and distribution network, and determine the coupling power matrix of the transmission and distribution network for the whole period.

Step 5: Solve the full-time power sales price of the transmission network, which can be characterized by the Lagrangian multiplier based on Locational Marginal Price (LMP), including marginal generation cost, loss cost and network blockage cost. Then, the model convergence judgment condition is constructed as follows:

$$
\left\{\begin{array}{l}
\left\|\boldsymbol{P}_{t}^{T-\boldsymbol{D}}-\boldsymbol{P}_{t-1}^{T-\boldsymbol{D}}\right\| \leq \lambda \\
\left\|L M P_{t}^{T-D}-L M P_{t-1}^{T-D}\right\| \leq \lambda
\end{array}\right.
$$

Step 6: When the model satisfies the constraints shown in Equation (26), the optimal cooperative planning scheme for transmission and distribution network is output and the iteration ends; otherwise, iter $=$ ite +1 and returns to Step 3.

The algorithm flow chart is shown in Figure 1. 

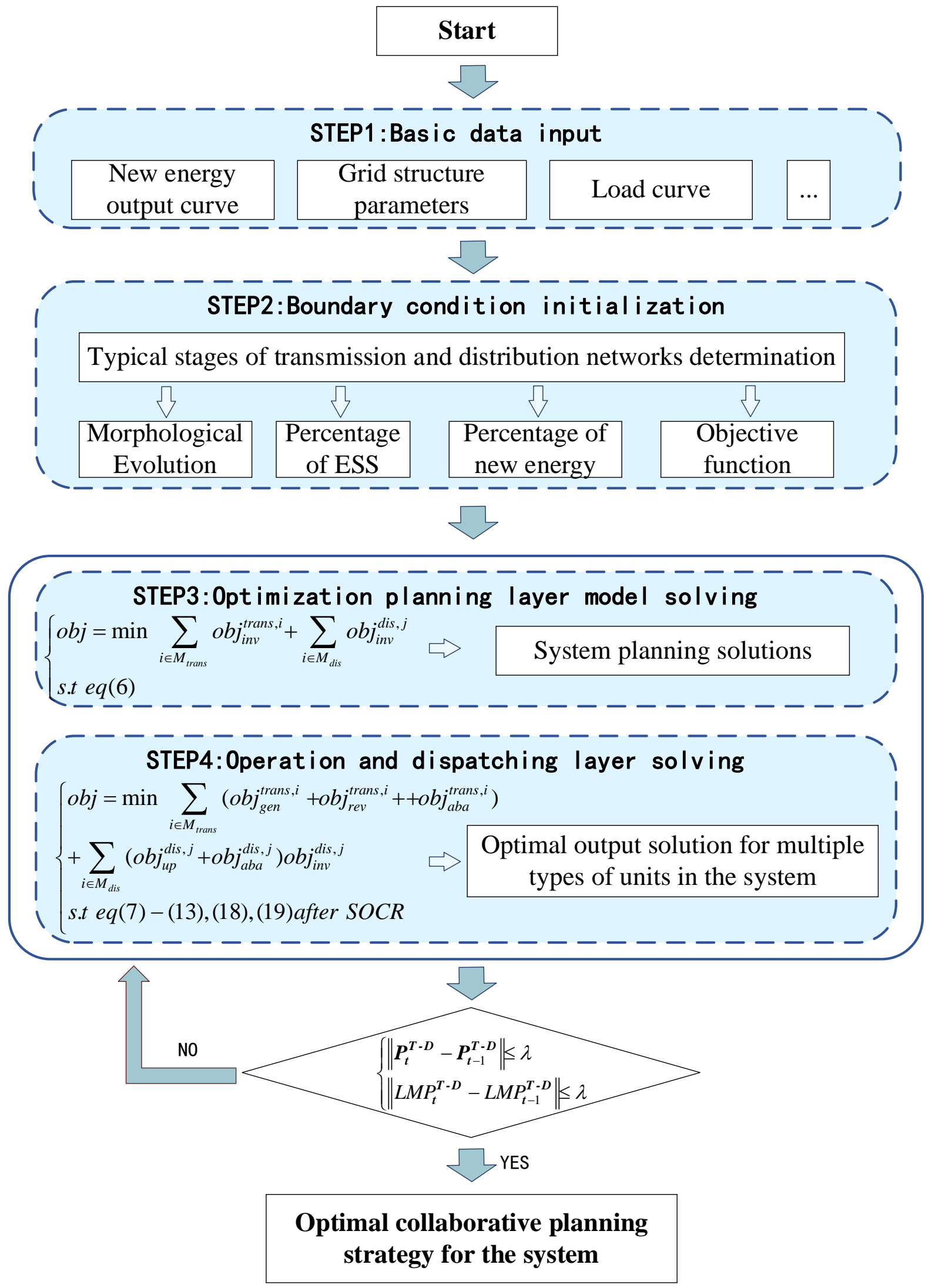

Figure 1. Algorithm flow chart. 


\section{Simulation Results}

In this section, the simulation model of the transmission and distribution network wind-PV-ESS collaborative planning model considering morphological evolution is established. In this paper, the transmission and distribution network system shown in Figure 2 is selected as an example for simulation analysis. The transmission network contains a total of six nodes, three generators and one load node; distribution network 1 has a total of nine nodes, including one root node and three load nodes; distribution network 2 has a total of seven nodes, including one root node and four load nodes. Both the transmission network and distribution network load use the proportional distribution mode, and the basic parameters of the grid and wind power, PV, and ESS are shown in the literature [27-29] and Tables 2-4, where the system multi-type units can be accessed via nodes which are extended by using the data of the literature [27]. The wind-PV-ESS can be accessed at all nodes, except the transmission network connection node and the root node of the distribution network.

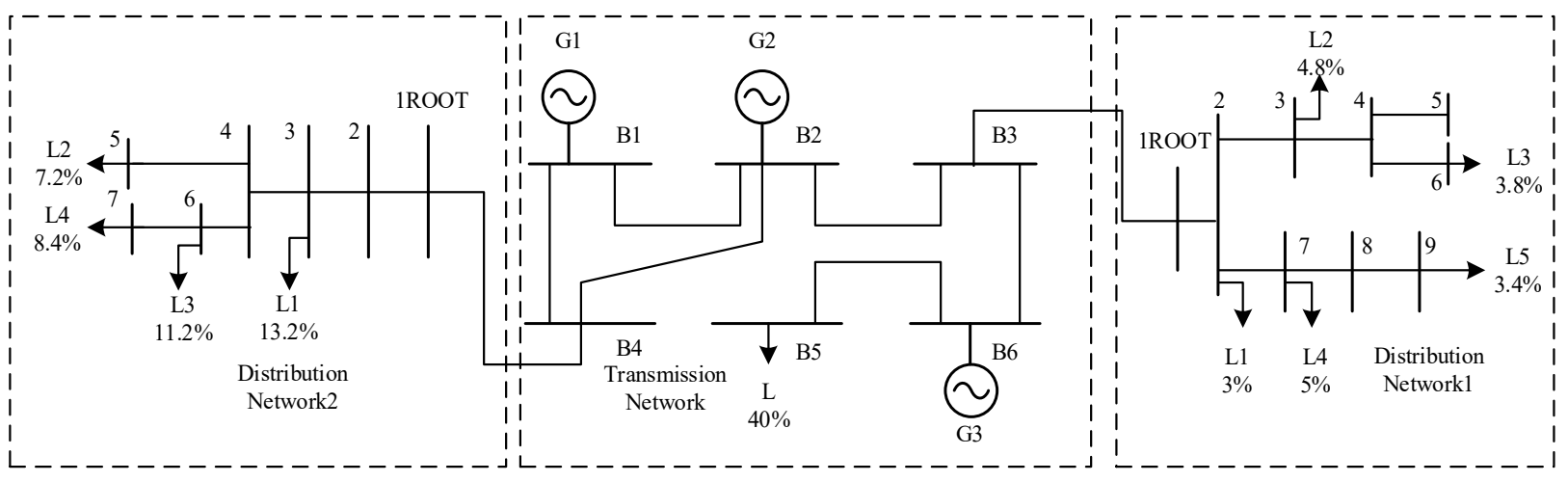

Figure 2. Example structure diagram.

Table 2. Transmission network parameters.

\begin{tabular}{cccc}
\hline Starting Node & Termination Node & Impedance (p.u) & Power Limit/MW \\
\hline 1 & 2 & $0.021+0.170 \mathrm{j}$ & 200 \\
1 & 4 & $0.032+0.258 \mathrm{j}$ & 200 \\
2 & 3 & $0.004+0.037 \mathrm{j}$ & 190 \\
2 & 4 & $0.025+0.197 \mathrm{j}$ & 200 \\
3 & 6 & $0.002+0.018 \mathrm{j}$ & 180 \\
4 & 5 & $0.005+0.037 \mathrm{j}$ & 190 \\
5 & 6 & $0.018+0.140 \mathrm{j}$ & 180 \\
\hline
\end{tabular}

Table 3. Distribution network 1 parameters.

\begin{tabular}{cccc}
\hline Starting Node & Termination Node & Impedance (p.u) & Power Limit/MW \\
\hline B3 & 1 & $0.07+0.20 \mathrm{j}$ & 60 \\
1 & 2 & $0.06+0.19 \mathrm{j}$ & 60 \\
2 & 3 & $0.07+0.21 \mathrm{j}$ & 30 \\
2 & 7 & $0.07+0.21 \mathrm{j}$ & 30 \\
3 & 4 & $0.07+0.20 \mathrm{j}$ & 40 \\
4 & 5 & $0.06+0.18 \mathrm{j}$ & 20 \\
4 & 6 & $0.06+0.18 \mathrm{j}$ & 30 \\
7 & 8 & $0.06+0.19 \mathrm{j}$ & 20 \\
8 & 9 & $0.06+0.19 \mathrm{j}$ & 20 \\
\hline
\end{tabular}


Table 4. Distribution network 2 parameters.

\begin{tabular}{cccc}
\hline Starting Node & Termination Node & Impedance (p.u) & Power Limit/MW \\
\hline B4 & 1 & $0.08+0.20 \mathrm{j}$ & 70 \\
1 & 2 & $0.05+0.15 \mathrm{j}$ & 70 \\
2 & 3 & $0.08+0.20 \mathrm{j}$ & 90 \\
3 & 4 & $0.05+0.16 \mathrm{j}$ & 70 \\
4 & 5 & $0.06+0.18 \mathrm{j}$ & 40 \\
4 & 6 & $0.06+0.18 \mathrm{j}$ & 50 \\
6 & 7 & $0.05+0.16 \mathrm{j}$ & 40 \\
\hline
\end{tabular}

\subsection{Wind-PV-ESS Planning Example in Distribution Network Considering the Morphological Evolution}

To analyze the impact of the grid in different periods of morphological evolution on the system wind-PV-ESS planning scheme, this paper first takes the distribution network1 as the research object and solves the system planning scheme in the sprouting period, development period, and maturity period, respectively, as can be seen in Table 5 and Figure 3.

Table 5. Planning scheme for wind-PV-ESS of distribution network 1 in different periods.

\begin{tabular}{cccc}
\hline & Sprouting Period & Development Period & Maturity Period \\
\hline Total system cost $(\mathrm{k} \$)$ & 3931.6 & 2657.2 & 2949.8 \\
ESS construction $(\mathrm{MW})$ & 0 & 50.48 & 49.99 \\
Total wind abandonment $(\mathrm{MW} \cdot \mathrm{h})$ & 0 & 5098.6 & 64,643 \\
Total PV abandonment $(\mathrm{MW} \cdot \mathrm{h})$ & 0 & 5187.7 & 50,359 \\
Power interaction $(\mathrm{MW} \cdot \mathrm{h})$ & 1054.3 & 309.85 & -117.32 \\
\hline
\end{tabular}

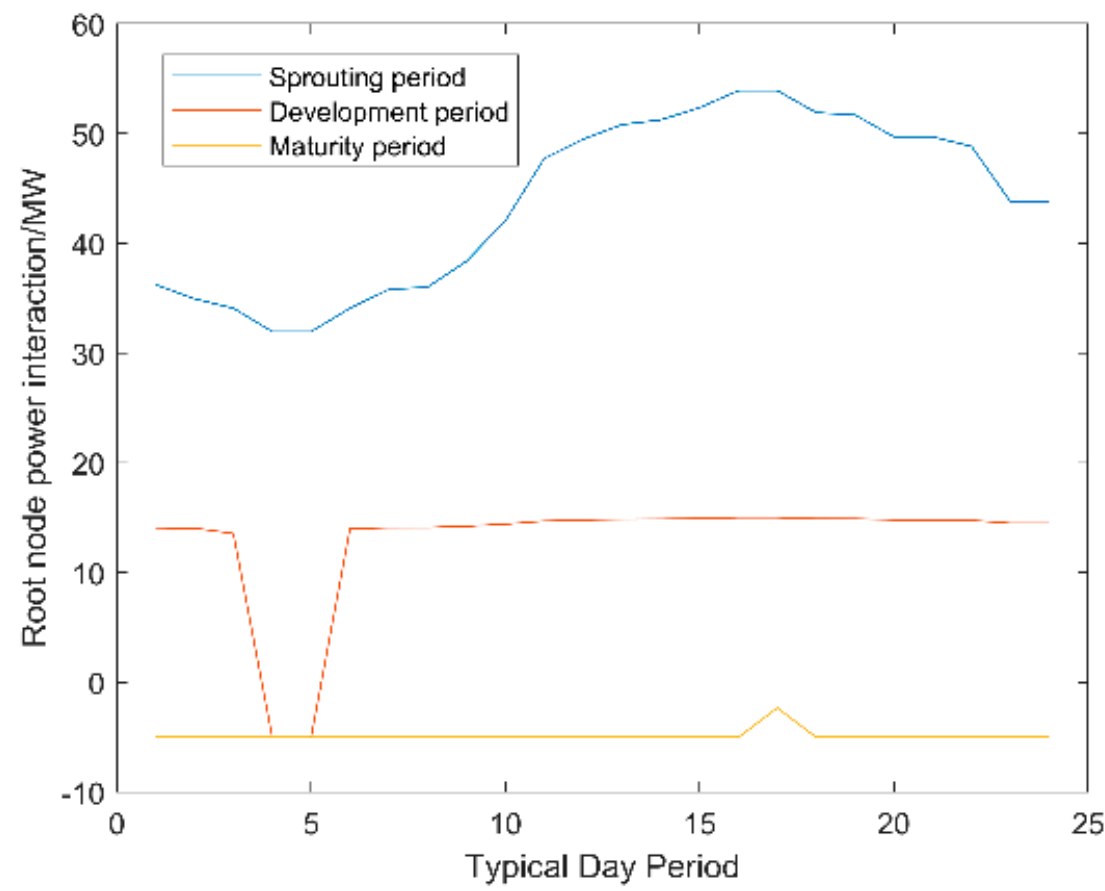

Figure 3. Power interaction of distribution network 1 root node in each typical period.

As can be seen from Table 5, in the single distribution network planning scenario, without considering transmission and distribution coordination, the total system cost shows a " $U$ " shaped distribution and the total system cost is the lowest in the development period of the distribution network; in the sprouting period, the distribution network needs to purchase a large amount of power from the transmission network to meet the system's active 
balance because there are no distributed wind and PV units; and, because the grid structure and source-load distribution cannot fully support the high proportion of new energy access, the distribution network in the maturity period will have a large amount of wind and PV abandonment, which affects the system's economy and environmental protection.

At the same time, Figure 3 shows the power interaction between the distribution network root node and transmission network, and it can be concluded that the power grid in the development and maturity periods can make full use of the transmission channels to return excess power to the transmission network in order to achieve the purpose of improving the system economics and promoting the safe consumption of clean energy in the grid.

\subsection{Wind-PV-ESS Collaborative Planning Example in Transmission and Distribution Network Considering the Morphological Evolution}

To further demonstrate the advantages of transmission and distribution network cooperative planning, this paper further solves the transmission and distribution network wind-PV-ESS cooperative planning model, taking into account the morphological evolution, and the specific solution results are shown in Figures 4-6 and Table 6. It is worth mentioning that, since the cost of power purchase from distribution network is reflected in the cost of thermal unit output of transmission network in the transmission and distribution synergistic planning scenario, the cost of distribution networks 1 and 2 only takes into account the cost of equipment commissioning and the penalty of wind and PV abandonment, and does not consider the cost of power purchase from the distribution network to higher levels.

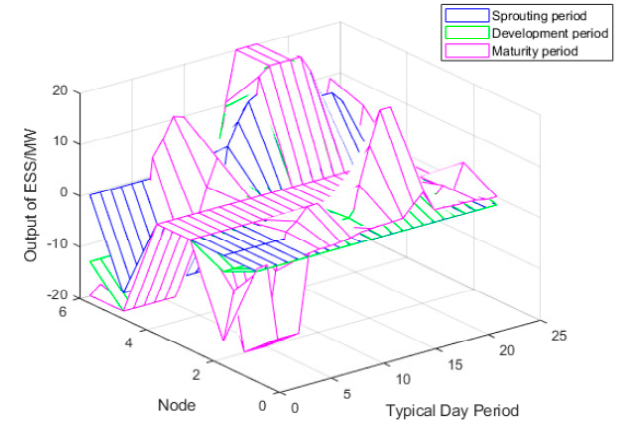

(a)

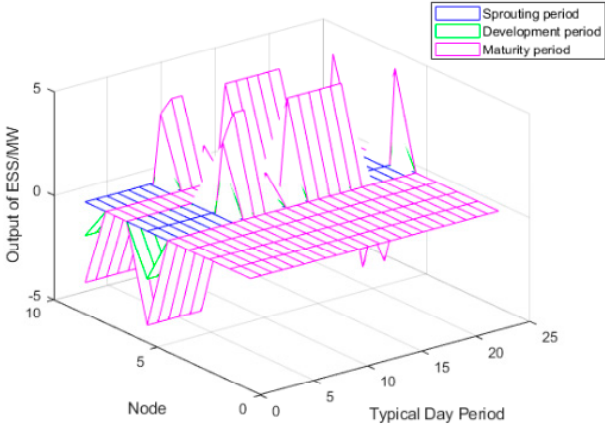

(b)

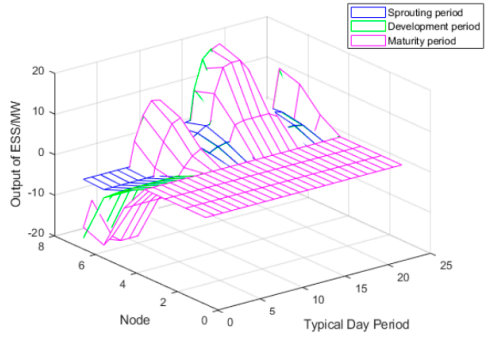

(c)

Figure 4. Output of ESS unit at each typical stage of the system: (a) transmission network; (b) distribution network 1 ; (c) distribution network 2.

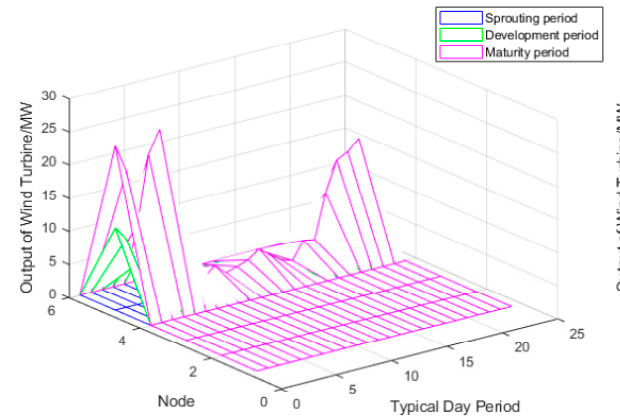

(a)

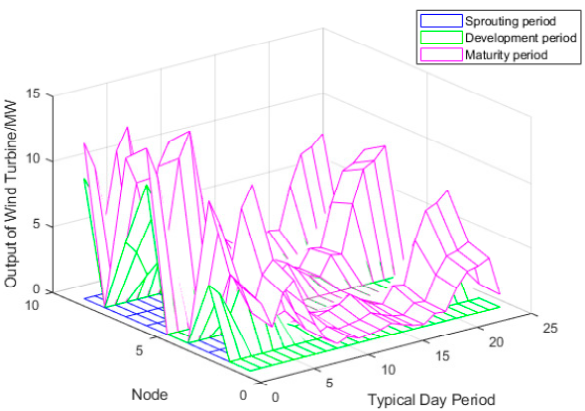

(b)

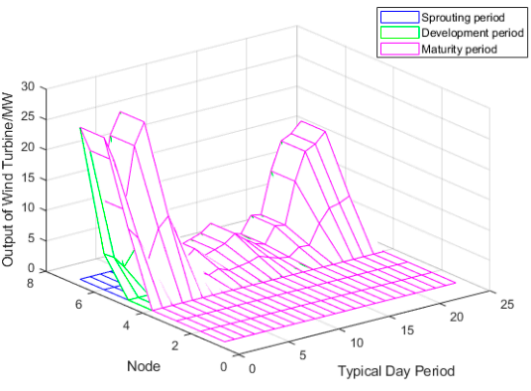

(c)

Figure 5. Output of wind turbine at each typical stage of the system: (a) transmission network; (b) distribution network 1 ; (c) distribution network 2 . 


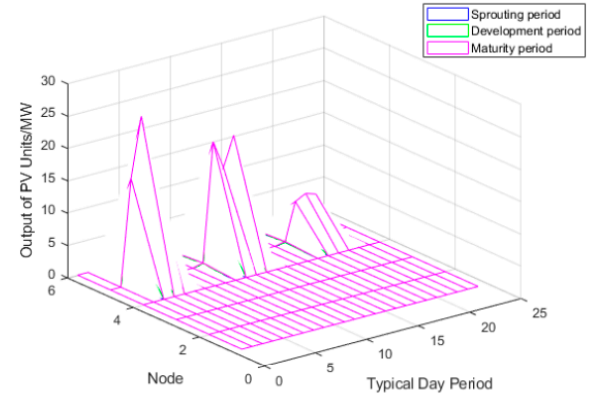

(a)

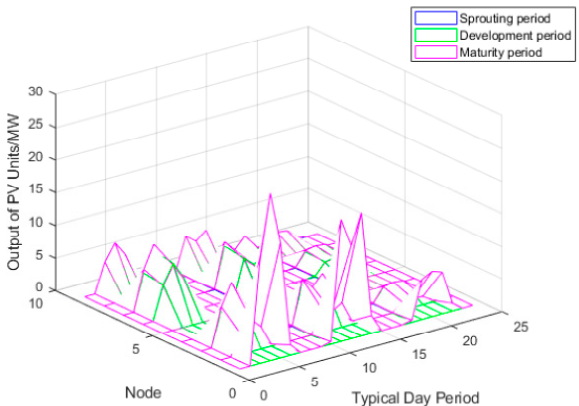

(b)

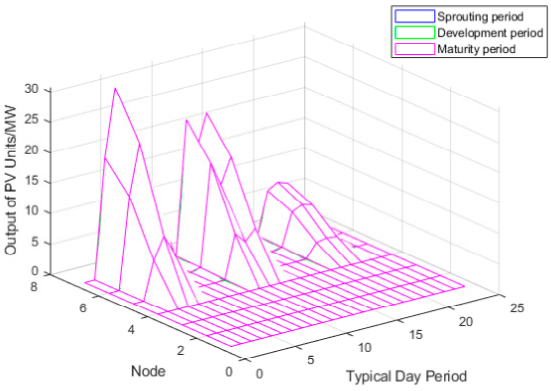

(c)

Figure 6. Output of PV unit at each typical stage of the system: (a) transmission network; (b) distribution network 1 ; (c) distribution network 2 .

Table 6. Collaborative planning scheme for wind-PV-ESS of transmission and distribution network in different periods.

\begin{tabular}{cccc}
\hline & Sprouting Period & Development Period & Maturity Period \\
\hline Total system cost $(\mathrm{k} \$$ ) & 24,738 & 21,396 & 18,987 \\
Transmission network costs & 24,681 & 19,667 & 15,583 \\
Distribution network1 costs & 1.87 & 805.42 & 1613.7 \\
Distribution network2 costs & 55.23 & 923.28 & 1790.4 \\
ESS construction (MW) & 28.2801 & 68.7389 & 127.8679 \\
Total wind abandonment (MW·h) & 0 & 0 & 1213.2 \\
Total PV abandonment $(\mathrm{MW} \cdot \mathrm{h})$ & 0 & 0 & 1056.9 \\
Power interaction $(\mathrm{MW} \cdot \mathrm{h})$ & 3459.1 & 2366.4 & 1367.7 \\
\hline
\end{tabular}

As can be seen from Table 3, unlike the scenario of independent planning for distribution network 1 , the overall system economy in the system planning scenario considering transmission and distribution coupling is continuously improved as the period of grid form evolution advances, and the transmission and distribution collaborative planning scenario can better improve the system economy, reasonably allocate system redundant resources, fully dispatch system flexibility regulation resources, promote safe consumption of clean energy, and realize the global optimization of the transmission and distribution network.

At the same time, from Figure 4 to Figure 6, it can be seen that compared with the system in the sprouting period, the system in the developmental and maturity periods can make better use of distributed wind power and PV units, which are more economically advantageous, and through the construction of a large number of centralized and distributed ESS and more adequate scheduling of ESS to achieve the purpose of promoting the safe consumption of clean energy, suppressing the uncertainty and the anti-peaking characteristics of wind-PV units. In addition, compared with the traditional distribution network in the sprouting period, the ADN with trendy returns can greatly relieve the pressure of new energy consumption in the distribution network, promote the system redundant power consumption the premise of ensuring the active balance of the distribution network during the low load period, reduce the cost of thermal power generation units in the transmission network, improve the efficiency of the system dispatchable resources in the heterogeneous decomposition architecture, and improve the overall efficiency of the transmission and distribution network. The efficiency of system dispatchable resources in the heterogeneous decomposition structure is improved, and the benefits of the transmission and distribution network are fully manifested.

\subsection{Algorithm Comparison}

To further highlight the advantages of the collaborative planning strategy proposed in this paper, the proposed architecture and the transmission and distribution separation 
optimization architecture were used to solve and compare for the system in the maturity period, respectively, and the specific results are shown in Table 7.

Table 7. Comparison of transmission and distribution collaborative planning/transmission and distribution separation planning strategy.

\begin{tabular}{ccc}
\hline & $\begin{array}{c}\text { Transmission and } \\
\text { Distribution Separation } \\
\text { Planning }\end{array}$ & $\begin{array}{c}\text { Transmission and } \\
\text { Distribution Collaborative } \\
\text { Planning }\end{array}$ \\
\hline Total system cost $(\mathrm{k} \$)$ & 24,088 & 18,987 \\
Transmission network costs & 16,039 & 15,583 \\
Distribution network 1 costs & 6359.3 & 1613.7 \\
Distribution network 2 costs & 4748.3 & 1790.4 \\
Total wind abandonment $(\mathrm{MW} \cdot \mathrm{h})$ & 1689.3 & 1213.2 \\
Total PV abandonment $(\mathrm{MW} \cdot \mathrm{h})$ & 1567.2 & 1056.9 \\
\hline
\end{tabular}

From the above results, it can be seen that, compared with the traditional transmission and distribution separation planning scheme, the system planning scheme which takes into account the transmission and distribution collaboration improves the economy of the transmission network by $456 \mathrm{k} \$$, the economy of distribution network 1 by $4745.6 \mathrm{k} \$$, and the economy of distribution network 2 by $2957.9 \mathrm{k} \$$. Therefore, the planning scheme constructed in this paper can fully take into account the transmission and distribution network synergy interaction to improve the system economy and promote the safe consumption of clean energy, and the transmission and distribution collaborative planning architecture built in this paper has obvious advantages over the traditional planning architecture.

\section{Conclusions}

The SOCR-based wind-PV-ESS collaborative planning model for transmission and distribution network is constructed, and a fast model solving architecture based on heterogeneous decomposition is proposed to finally determine a collaborative planning strategy for wind-PV-ESS that takes into account the morphological evolution of the transmission and distribution network driven by multiple factors. The results show that, compared with the traditional transmission and distribution cooperative optimization algorithm based on DC power flow, the cooperative planning model established in this paper can fully consider the structural characteristics of the transmission and distribution network and ensure the computational efficiency and convergence ability of the model while ensuring solution accuracy. Compared with the traditional algorithm, the total operating cost of the transmission network, distribution network 1 and distribution network 2 under the proposed transmission and distribution cooperative planning scheme is reduced by $456 \mathrm{k} \$, 4745.6 \mathrm{k} \$$, and $2957.9 \mathrm{k} \$$ respectively. At the same time, the proposed architecture can fully take into account the cooperative interaction of transmission and distribution networks, and promote the complementary advantages of uncertain clean energy and flexible adjustable resources in the system. It has a wide application space for the future grid form in which the information and data of transmission and distribution networks are increasingly coupled, and the proportion of clean energy and ESS access to the system is increasing.

Future work may focus on trying to improve the computational speed and convergence of algorithms and to further enrich the application scenarios of models and algorithms.

Author Contributions: Conceptualization, D.C. and Z.W.; methodology, S.M. and R.C.; software, Z.Z.; validation, K.Z.; formal analysis, Z.W.; resources, S.M.; data curation, D.C.; writing-original draft preparation, Z.Z.; writing-review and editing, S.M.; visualization, R.C.; supervision, K.Z.; project administration, D.C.; funding acquisition, D.C. All authors have read and agreed to the published version of the manuscript.

Funding: The work presented was supported by the Science and Technology Project of State Grid Corporation of China, China (5100-202156002A-0-0-00). 
Institutional Review Board Statement: Not applicable.

Informed Consent Statement: Not applicable.

Data Availability Statement: Not applicable.

Conflicts of Interest: The authors declare no conflict of interest.

\section{References}

1. Li, Z.; Ding, Y.; Han, D. Energy Consumption Transformation, Cleaner Production, and Regional Carbon Productivity in China: Evidence Based on a Panel Threshold Model. IEEE Access 2021, 9, 16254-16265. [CrossRef]

2. Zhou, W.; Chen, Q.; Luo, D.; Jiang, R.; Chen, J. Global Energy Consumption Analysis Based on the Three-Dimensional Network Model. IEEE Access 2020, 8, 76313-76332. [CrossRef]

3. LI, J.; Song, X.; Zhang, Y.; Gao, F. Operation optimization of active distribution network considering maximum consumption of distributed generation. In Proceedings of the 2019 IEEE 8th International Conference on Advanced Power System Automation and Protection (APAP), Xi'an, China, 21-24 October 2019; pp. 1053-1057. [CrossRef]

4. Kabirifar, M.; Fotuhi-Firuzabad, M.; Moeini-Aghtaie, M.; Pourghaderia, N. Joint Distributed Generation and Active Distribution Network Expansion Planning Considering Active Management of Network. In Proceedings of the 2019 27th Iranian Conference on Electrical Engineering (ICEE), Yazd, Iran, 30 April-2 May 2019; pp. 702-708. [CrossRef]

5. Hua, X.; Yuxi, C.; Jian, W.; Agelidis, V. Design of energy dispatch strategy of active distribution network using chance-constrained programming. In Proceedings of the 2015 IEEE PES Asia-Pacific Power and Energy Engineering Conference (APPEEC), Brisbane, Australia, 15-18 November 2015; pp. 1-5. [CrossRef]

6. Yang, Z. Probabilistic Power Flow Algorithm of Active Distribution Network Based on Semi-invariant and Gram-Charlier Expansion. In Proceedings of the 2020 IEEE 3rd Student Conference on Electrical Machines and Systems (SCEMS), Jinan, China, 4-6 December 2020; pp. 222-226. [CrossRef]

7. Abbas, A.S.; El-Sehiemy, R.A.; El-Ela, A.A.; Ali, E.S.; Mahmoud, K.; Lehtonen, M.; Darwish, M.M.F. Optimal Harmonic Mitigation in Distribution Systems with Inverter Based Distributed Generation. Appl. Sci. 2021, 11, 774. [CrossRef]

8. Ali, E.S.; El-Sehiemy, R.A.; El-Ela, A.A.A.; Mahmoud, K.; Lehtonen, M.; Darwish, M.M.F. An Effective Bi-Stage Method for Renewable Energy Sources Integration into Unbalanced Distribution Systems Considering Uncertainty. Processes 2021,9 , 471. [CrossRef]

9. Emara, D.; Ezzat, M.; Abdelaziz, A.Y.; Mahmoud, K.; Lehtonen, M.; Darwish, M.M.F. Novel Control Strategy for Enhancing Microgrid Operation Connected to Photovoltaic Generation and Energy Storage Systems. Electronics 2021, 10, 1261. [CrossRef]

10. Al-Gabalawy, M.; Mahmoud, K.; Darwish, M.M.F.; Dawson, J.A.; Lehtonen, M.; Hosny, N.S. Reliable and Robust Observer for Simultaneously Estimating State-of-Charge and State-of-Health of LiFePO4 Batteries. Appl. Sci. 2021, 11, 3609. [CrossRef]

11. Bendary, A.F.; Abdelaziz, A.Y.; Ismail, M.M.; Mahmoud, K.; Lehtonen, M.; Darwish, M.M.F. Proposed ANFIS Based Approach for Fault Tracking, Detection, Clearing and Rearrangement for Photovoltaic System. Sensors 2021, 21, 2269. [CrossRef]

12. Wang, Z.; Luo, D.; Li, R.; Zhang, L.; Liu, C.; Tian, X.; Li, Y.; Su, Y.; He, J. Research on the active power coordination control system for wind/photovoltaic/energy storage. In Proceedings of the 2017 IEEE Conference on Energy Internet and Energy System Integration (EI2), Beijing, China, 26-28 November 2017; pp. 1-5. [CrossRef]

13. Awadallah, M.A.; Venkatesh, B. Energy Storage in Distribution System Planning and Operation: Current Status and Outstanding Challenges. Can. J. Electr. Comput. Eng. 2019, 42, 10-19. [CrossRef]

14. Xiao, H.; Pei, W.; Dong, Z.; Kong, L. Bi-level planning for integrated energy systems incorporating demand response and energy storage under uncertain environments using novel metamodel. CSEE J. Power Energy Syst. 2018, 4, 155-167. [CrossRef]

15. Oskouei, M.Z.; Mohammadi-Ivatloo, B.; Erdinç, O.; Erdinç, F.G. Optimal Allocation of Renewable Sources and Energy Storage Systems in Partitioned Power Networks to Create Supply-Sufficient Areas. IEEE Trans. Sustain. Energy 2021, 12, 999-1008. [CrossRef]

16. Xuewei, S.; Xuefang, S.; Wenqi, D.; Peng, Z.; Hongyan, J.; Jinfang, W.; Yang, W. Research on Energy Storage Configuration Method Based on Wind and Solar Volatility. In Proceedings of the 2020 10th International Conference on Power and Energy Systems (ICPES), Chengdu, China, 25-27 December 2020; pp. 464-468. [CrossRef]

17. Deshun, W.; Yumeng, Z.; Qiong, T.; Jinhua, X.; Jelei, Y. Research on Planning and Configuration of Multi-objective Energy Storage System Solved by Improved Ant Colony Algorithm. In Proceedings of the 2018 China International Conference on Electricity Distribution (CICED), Tianjin, China, 17-19 September 2018; pp. 2279-2283. [CrossRef]

18. Nawaz, A.; Wang, H. Distributed stochastic security constrained unit commitment for coordinated operation of transmission and distribution system. CSEE J. Power Energy Syst. 2021, 7, 708-718. [CrossRef]

19. Li, Z.; Guo, Q.; Sun, H.; Wang, J. Coordinated Economic Dispatch of Coupled Transmission and Distribution Systems Using Heterogeneous Decomposition. IEEE Trans. Power Syst. 2016, 31, 4817-4830. [CrossRef]

20. Li, Z.; Guo, Q.; Sun, H.; Wang, J. A New LMP-Sensitivity-Based Heterogeneous Decomposition for Transmission and Distribution Coordinated Economic Dispatch. IEEE Trans. Smart Grid 2016, 9, 931-941. [CrossRef] 
21. Lin, C.; Wu, W.; Shahidehpour, M.; Guo, Y.; Wang, B. A Non-Iterative Decoupled Solution of the Coordinated Robust OPF in Transmission and Distribution Networks with Variable Generating Units. IEEE Trans. Sustain. Energy 2020, 11, 1579-1588. [CrossRef]

22. Wang, C.S.; Wang, R.; Yu, H.; Song, Y.; Yu, L.; Li, P. Challenges on Coordinated Planning of Smart Distribution Networks Driven by Source-network-load Evolution. Proc. CSEE 2020, 40, 2385-2396. (In Chinese)

23. Zhou, X.X.; Lu, Z.X.; Liu, Y.H.; Chen, S. Development Models and Key Technologies of Future Grid in China. Proc. CSEE 2014, 34, 4999-5008. (In Chinese)

24. Xie, K.; Billinton, R. Determination of the Optimum Capacity and Type of Wind Turbine Generators in a Power System Considering Reliability and Cost. IEEE Trans. Energy Convers. 2011, 26, 227-234. [CrossRef]

25. Ding, T.; Sun, K.; Yang, Q.; Khan, A.W.; Bie, Z. Mixed Integer Second Order Cone Relaxation With Dynamic Simulation for Proper Power System Islanding Operations. IEEE J. Emerg. Sel. Top. Circuits Syst. 2017, 7, 295-306. [CrossRef]

26. Zhou, X.X.; Chen, S.Y.; Lu, Z.X. Review and Prospect for Power System Development and Related Technologies: A Concept of Three-generation Power Systems. Proc. CSEE 2013, 33, 1-11. (In Chinese)

27. Kargarian, A.; Fu, Y. System of systems based security-constrained unit commitment incorporating active distribution networks. IEEE Trans. Power Syst. 2014, 29, 2489-2498. [CrossRef]

28. Zheng, Z.; Miao, S.H.; Zhang, S.Y.; Yao, F.X.; Zhang, D.; Han, J. Collaborative Optimization Strategy for Location and Capacity Determination of Energy Storage System Considering Transmission and Distribution Integration Based on Extreme Learning Machine. Electric Power Automation Equipment. 2021. Available online: https://kns.cnki.net/kcms/detail/32.1318.TM.20211110.1 652.009.html (accessed on 20 December 2021). (In Chinese).

29. Dehghani-Sanij, A.R.; Tharumalingam, E.; Dusseault, M.B.; Fraser, R. Study of energy storage systems and environmental challenges of batteries. Renew. Sustain. Energy Rev. 2019, 104, 192-208. [CrossRef] 